\title{
EGU21-9559
}

https://doi.org/10.5194/egusphere-egu21-9559

EGU General Assembly 2021

(c) Author(s) 2021. This work is distributed under

the Creative Commons Attribution 4.0 License.

\section{D distinct element back-analysis (static and dynamic) of a reconstructed rock slope}

\author{
Anne-Sophie Mreyen ${ }^{1}$, Léna Cauchie ${ }^{1}$, Mihai Micu ${ }^{2}$, and Hans-Balder Havenith ${ }^{1}$ \\ ${ }^{1}$ Department of Geology, University of Liege, Liege, Belgium (as.mreyen@uliege.be) \\ ${ }^{2}$ Institute of Geography, Romanian Academy, Bucharest, Romania
}

To better comprehend mechanisms at the origin of natural slope failures, a vast number of potential slope weakening and failure triggering factors ought to be considered. Especially for rather ancient slope failures, such factors can be difficult to identify and strongly depend on the regional to local climatic as well as seismo-tectonic context.

An example of such ancient failure of unknown origin is the Balta rockslide that is located in the seismic region of Vrancea-Buzau, Romanian Carpathians. Even though more superficial landslides are found abundantly in the studied valley, the Balta failure stands out in terms of magnitude and observed geomorphological markers (profound detachment scarp, debris mass accumulation). During the last years, the Balta rockslide has been intensively studied with geophysical measurements (seismic and electrical methods) in order to characterise the landslide and in-situ rock material as well as the extensive dimension of the failure (with an estimated volume of 28.5-33.5 million $\mathrm{m}^{3}$ ).

In this work, we show the results of a numerical back-analysis of the Balta rockslide based on its reconstructed slope topography, implemented with 3D geomodelling, and on prior established geophysical and geomorphological studies; the reconstruction was furthermore conditioned by the morphology of neighbouring slopes in order to better constrain related uncertainties. The structural aspect of the anti-dip bedding of the sandstone dominated flysch slope was remodelled with $40^{\circ}$ dipping discontinuities, while $55^{\circ}$ dipping crossing discontinuities represent the main joint family observed in the field. The back-analysis was performed with the 3D distinct element code 3DEC (version 5.2, developed by Itasca) and aims at both, understanding static factors affecting slope stability, as well as the behaviour of the pre-failure slope if subjected to dynamic loading by using a synthetic Ricker multiplier as well as real earthquake acceleration data. The actual slope shape in its post-failure state could be approximated after 120 seconds of ground acceleration and is highlighted by lateral spreading of debris mass as well as towards the valley; the latter supposedly caused a temporary landslide dam formation, and possibly accounts for the river diversion observed in the field. This numerical approach furthermore allows us to outline the main controlling factors during seismic slope excitation that are predominated by topographic and structural site effects. 